\title{
Ovarian Fibrosarcoma
}

National Cancer Institute

\section{Source}

National Cancer Institute. Ovarian Fibrosarcoma. NCI Thesaurus. Code C5233.

A usually aggressive malignant neoplasm arising from the ovary. It is characterized by the presence of spindle-shaped fibroblasts and collag enous stroma formation in a herring bone growth pattern. 